\title{
Antonio Candido: \\ Da integração do sistema à literatura contra o sistema
}

Ronaldo Oliveira de Castro*

\section{Resumo}

Em A formação da literatura brasileira, de 1959, Antonio Candido apresenta o processo através do qual a literatura nacional teria se constituído enquanto sistema. 0 processo de construção do sistema literário opera, na argumentação desse livro, como uma espécie de fermento da própria nação: construir a nação aparecia como uma missão que caracterizava uma aspiração constitutiva desse sistema literário. Em ensaios posteriores, escritos durante a ditadura militar a atitude de Candido diante do fenômeno literário apresenta algumas diferenças significativas, a ênfase não é mais posta na construção do sistema, do cânone ou da ordem literária. Não busca mais mostrar como diferentes autores e obras se integram no interior do mesmo sistema literário. Os ensaios irão explorar não a integração sistêmica, mas como alguns textos ou se contrapõem às características predominantes do sistema, ou questionam aspectos da construção da ordem (literária ou nacional) que eram tomados como pressupostos na argumentação de Formação da literatura brasileira.

\section{Palavras-chave}

Literatura. Literatura brasileira. Ensaio. Antonio Candido.

\section{Abstract}

In A formação da literatura brasileira, originally published in 1959, Antonio Candido outlines the process through which national literature would have become constituted as a system. The building process of the literary system operates in this book's argument as a kind of yeast of the nation itself: to build the nation is an act portrayed as a mission, in itself a key feature of this literary system. In later essays, written during military dictatorship, Candido's attitude in face of the literary phenomenon presents several relevant diferences: emphasis is no longer placed on the construction of the system, the canon or the literary order. He no longer seeks to show how different authors and works are integrated into the same literary system. These essays do not explore the systemic integration; rather, they examine the way in which some texts either counter the system's main characteristics or question aspects of the building

* Ronaldo Oliveira de Castro é sociólogo e professor do Instituto de Ciências Sociais da UERj (ICS-UERJ). E-mail: ronaldooliveiradecastro@gmail.com. 
of the (literary or national) order which were until then taken for granted in the argument developed in Formação da literatura brasileira.

\section{Keywords}

Literature. Brazilian literature. Essay. Antonio Candido.

\section{A formação da literatura e a nação}

Antonio Candido, na Formação da literatura brasileira, discute a constituição de algo que irei definir como a ordem literária nacional, um cânone que não apenas reúne textos que integram uma tradição como interagem com o processo de construção da nação. Se as histórias da literatura do século XIX tomam a nação como anterior ao texto e como um ente que deveria nele se imprimir (cf. COSTA LIMA, 1992), a perspectiva de Candido, na Formação, ressalta um projeto no qual a nação não seria anterior à literatura, mas ambas se envolvem num processo simultâneo de edificação nacional e literária. Para o autor, há um projeto político de construção nacional que se revela na ideia, desenvolvida durante o Romantismo, de que a independência do Brasil deveria se manifestar em suas belas letras. Essa ideia seria uma chave para a compreensão da formação da literatura no Brasil. A construção da nação, fenômeno do século XIX, se torna um fator que orienta a análise que o autor realiza dos períodos precedentes, em sua tentativa de expressar literariamente a realidade local

“O leitor perceberá que me coloquei deliberadamente no ângulo dos nossos primeiros românticos e dos críticos estrangeiros que, antes deles, localizaram na fase arcádica o início da nossa verdadeira literatura, graças à manifestação de temas, notadamente o Indianismo, que dominarão a produção oitocentista. Esses críticos conceberam a literatura do Brasil como expressão da realidade local, e ao mesmo tempo, elemento positivo na construção nacional".

(CANDIDO, 1959, p. 25).

A ideia de sistema literário apresentada em Formação pode ser compreendida como um recurso para compreender a relação entre literatura e sociedade, em que a função social da primeira possui três dimensões. 
Primeiro, a literatura seria uma fonte de cultura individual; segundo, ela seria fermento da cultura nacional e, por fim, seria uma forma de atualização da cultura ocidental nos trópicos. A formação do sistema literário nacional teria se dado a partir de uma síntese de tendências universalistas e particularistas, ou seja, tendências que buscavam como o Arcadismo construir uma literatura moldada por padrões universalistas e outras tendências que, como o Romantismo, almejavam expressar a singularidade local. Apesar de representarem momentos distintos da dialética entre universalismo e particularismo, os árcades e os românticos poderiam ser pensados como integrantes de um movimento mais amplo. Ainda que esteticamente os dois estilos se afastem, sua "vocação histórica os aproxima" (CANDIDO, 1962, p. 16). Para Candido, a unidade fundamental entre os dois períodos não estaria na estética, mas na forma como a literatura é concebida, na "missão" literária que os dois "momentos" decisivos da formação literária brasileira assumiram. Esse senso de missão seria uma característica que, para o autor, aproximaria os dois estilos e que poderia ser pensado como uma tradição constitutiva do sistema literário, que se definiria pelo desenvolvimento de uma tradição, no sentido de uma "transmissão de algo entre os homens [...]. Sem esta tradição não há literatura como fenômeno de civilização" (CANDIDO, 1959, p. 24).

O sentido do conceito de formação apresentado pelo autor estaria na constituição dessa tradição ${ }^{1}$, na elaboração do sistema literário. Esse sistema seria elaborado pela articulação do triângulo autor-obra-público. A literatura brasileira se constituiria com o Arcadismo porque, com este, ela teria tomado as dimensões de um sistema "nacional" que permitiria a consolidação do mencionado triângulo, desenvolvendo a possibilidade de transmissão das obras produzidas tanto no espaço quanto no tempo, produzindo a tradição que permitiria reconhecer a produção literária local como uma literatura nacional. Antes do sistema literário, teriam ocorrido apenas "manifestações literárias", pois a literatura propriamente dita

\footnotetext{
${ }^{1}$ Neste ponto pode-se constatar uma proximidade entre Candido e Sílvio Romero, pois este último, em A literatura brasileira e a crítica moderna, já definia a literatura como um fenômeno de tradição. Para esse autor literatura não se define pela existência de autores que produzem "sem relação entre si, que levaram uma vida mental sem antecedentes e consequentes em seu país", mas "há literatura [...] sempre que num povo encontra-se a consciência de si mesmo e uma mais ou menos extensa rede disso que chamarei tradições mentais, vazadas em algum produto da imaginação" (ROMERO, 1880, p. 93-94). Note-se a semelhança entre a posição de Romero e a distinção entre manifestações e sistema literário realizada por Candido.
} 
depende da integração do sistema.

A formação de um sistema literário integrado possibilitaria um maior desenvolvimento da literatura. Esta deixaria de ser a produção de sujeitos isolados, formando uma espécie de ambiente cultural partilhado de onde cada autor partiria para suas próprias realizações. Esse ambiente permitiria que o público também se desenvolvesse. O sistema literário seria uma atmosfera cultural na qual, através das obras, não só o público entraria em contato com os autores, mas também estes se comunicariam entre si, seriam herdeiros uns dos outros. Essa atmosfera poderia ser pensada como uma fonte de valores culturais para o conjunto da sociedade brasileira. Em suma, o sistema é tradição. $\mathrm{O}$ entrelaçamento das ideias de tradição e sistema permite ao autor, no contexto da Formação, explorar tanto os aspectos estruturais do sistema literário quanto tomá-lo como base para o desenvolvimento cultural dos indivíduos, inclusive como condição para o processo de autoformação dos autores, que se dá a partir do diálogo com a tradição.

A Formação é a história da constituição dessa tradição. É a história da produção da ordem literária como contribuição para a consolidação da ordem nacional. Deste modo, não aparecem no texto referências a obras ou interpretações que se desviavam desse projeto de construção da literatura e da nação. Mais do que isso, a concepção de literatura que caracterizaria esse processo seria marcada pela adequação do texto literário à sociedade e ao leitor, o texto teria que preencher as expectativas formuladas pelo ideal de construção nacional, e para isso teria que se conformar aos horizontes do leitor, sem tentar transgredi-los. A consciência de estar fazendo "a nação ao fazer a literatura" (CANDIDO, 1962) produziria uma concepção bastante específica dessa última. $\mathrm{O}$ nacionalismo literário teria representado para o autor um fator restritivo da imaginação, pois, comprometido com a ideia de missão, o escritor brasileiro exerceria aquilo que, mais tarde, Costa Lima (1984) chamou de um veto ao ficcional.

A ideia de missão, representando o predomínio da função social, implicaria a redução da mais autêntica função da literatura, a função estética. Todavia, na Formação não há uma crítica sistemática ao "controle do imaginário". Pois se o senso de missão reduziu o contato com o imaginário, tendo como efeito a produção de uma literatura que não transcende o real, pretendendo descrever mais do que criar, a dimensão empenhada, o compromisso com a ideia de missão, também teria dotado a literatura de uma responsabilidade com a construção do país, desenvolvendo uma espécie de 
postura militante por parte do escritor brasileiro, comprometendo-o com a vida nacional. Se "esta participação [do escritor] foi frequentemente um empecilho, do ponto de vista estético, tanto quanto foi, noutros casos, uma inestimável vantagem" (CANDIDO, 1962, p. 18). O privilégio da ideia de nação coloca o fator social em primeiro plano.

A consciência de fazer a nação ao fazer literatura não seria exclusiva dos literatos, a própria crítica brasileira a teria incorporado. Para o autor, o ponto de partida da crítica no Brasil sempre foi a concepção da literatura como expressão e peça de construção nacional, e propõe que seu livro seja entendido como um estudo do "sentido" e da "validade histórica dessa velha concepção cheia de equívocos", como uma "história dos brasileiros no seu desejo de ter uma literatura" (CANDIDO, 1959, p. 51). É fácil imaginar que equívocos seriam esses, pois estariam associados à questão já discutida da restrição à imaginação. A ideia de missão, característica do sistema, faz da literatura simultaneamente reveladora e produtora do real. Ao descrever o real, essa literatura se integra ao processo de formação da nação.

Se o autor, por um lado, adota como perspectiva a construção da nação e da ordem literária nacional, por outro a literatura é pensada como uma forma através da qual o "espírito do ocidente" veio habitar o novo mundo. O livro de Candido é mais do que a anunciada "história dos brasileiros no seu desejo de ter uma literatura", é também a história de como o Brasil integrou-se aos valores ocidentais. Esses valores europeus fecundam a produção literária e a própria cultura brasileira, enriquecendo-as, e a elas se incorporando. Esse argumento já se encontrava presente no Ensaio sobre a música brasileira (1928) de Mário de Andrade. Nesse Ensaio, defende-se a ideia de que o contato com tradições culturais mais refinadas contribui para o desenvolvimento da música e da própria cultura brasileira, tornando-as mais sofisticadas. A particularidade brasileira se entrelaça, segundo Mário, à universalidade da cultura europeia, que contribui para acentuar e tornar mais elaborados aspectos da própria cultura brasileira.

Candido e de Mário de Andrade percebem a cultura brasileira como algo que se cultiva a partir da interação entre uma dimensão interna e uma externa. Candido percebe o processo de constituição do sistema literário como um aperfeiçoamento da cultura coletiva e, consequentemente, do indivíduo que, através da literatura, desenvolve sua personalidade e visão de mundo. O sistema é descrito como tradição, que incorpora o passado como portador de um espírito que constitui o presente e que permanece significativo. A tradição integra a modelagem do presente, pois ela fornece 
conteúdos através dos quais os indivíduos se cultivam.

Na Formação há um eixo que articula a história a partir da ideia de nação com o processo de integração do Brasil à cultura ocidental. Neste sentido, Candido afirma que seu livro apresenta o processo de constituição do sistema literário como uma síntese entre tendências particularistas e universalistas, de modo que o conceito de nação é eleito como instrumento privilegiado para a compreensão do processo histórico de constituição da literatura, e esta, por sua vez, articula-se com valores universais que conectariam o Brasil à Civilização Ocidental.

A ideia de uma síntese entre correntes universalistas e particularistas se revela, a princípio, na contraposição entre os dois momentos decisivos do processo de formação do sistema literário brasileiro. Candido apresenta o Arcadismo como representante da primeira corrente, enquanto o Romantismo representaria a segunda. A estética arcádica orientada por padrões universais teria enraizado a literatura ocidental na colônia ao incorporar a produção intelectual local aos modelos europeus tradicionais, "ou seja, a um sistema expressivo, segundo o qual se havia forjado a literatura no Ocidente" (CANDIDO, 1959-II, p. 11). No Arcadismo, a particularidade local é expressa numa linguagem universal, e é justamente essa universalidade que está em destaque. $\mathrm{O}$ índio ou a paisagem tropical adquirem poeticidade quando podem ser apresentados através de uma linguagem clássica, que revela que, também nesta parte do mundo, se vivenciam os problemas fundamentais do homem.

Ao contrário dos árcades, que submetem o particular a uma forma de expressão universal, os românticos pretendem valorizar a cor local, acentuar a originalidade e são tributários do nacionalismo. Os românticos buscam exprimir o particular através de sua própria singularidade, a ênfase recai sobre o que diferencia, enquanto os árcades buscavam mostrar que, por trás das diferenças aparentes, poder-se-ia encontrar os grandes temas da arte ocidental. Porém, essas duas correntes estariam em continuidade no que diz respeito aos temas, e, principalmente, em relação à produção de uma literatura empenhada na construção da nação. Neste sentido, opera-se uma síntese entre os dois momentos: os árcades transplantam para o Brasil a linguagem literária europeia, e os românticos buscam expressar a singularidade; o particularismo sucede ao universalismo. Todavia, o argumento de Candido sobre o Romantismo logo se desdobra. O Romantismo é, sobretudo, um movimento europeu, e, neste sentido, a busca do singular corresponde à inserção da literatura nacional numa 
tendência "universal". No momento em que o autor nota de forma mais acentuada a identificação da literatura com a afirmação do nacional, conclui que, parcialmente, a busca da singularidade corresponde à adesão que os autores nacionais fazem a um movimento da cultura europeia. A ideia de que um país independente deveria ter uma literatura também independente é proveniente do Romantismo europeu.

Essa tese romântica, com todas as suas afinidades com as aspirações de um país que há pouco proclamara sua independência, levanta um outro problema que aflige os românticos brasileiros, pois, para estes, a literatura deveria ser expressão da nação, de modo que o país deveria, também no campo das letras, possuir independência em relação a Portugal, dele se diferenciando. O Romantismo seria neste sentido uma "verdadeira declaração de independência literária". O problema é como sustentar essa reivindicação de autonomia se a língua permanece a mesma. Ou seja, quais seriam os critérios que sustentariam a ideia de uma literatura brasileira ao invés de uma literatura em língua portuguesa produzida no Brasil, como defendia Álvares de Azevedo, para quem "a individuação literária depende da linguística" (CANDIDO, 1959-II, p. 305). Eu diria que a resposta que, segundo a Formação, os românticos brasileiros dão a essa questão é a mera reafirmação de seu postulado: a literatura é a expressão da nação, como somos um povo independente, temos uma literatura independente, ou o que dá no mesmo, a independência da nação é prova da independência da literatura. O critério decisivo para a definição da literatura é político, é o surgimento da nação. Ao assumir o ponto de vista dos românticos, o autor concebe a expressão literária como um campo privilegiado para "a demonstração do sentido da existência social"22.

Para efeito de comparação, tome-se a História da literatura portuguesa de Antonio José Saraiva e Oscar Lopes, cuja primeira edição antecede em dez anos a Formação. Para esses autores, a história da literatura portuguesa é a história da constituição da língua portuguesa através da literatura, o português literário. Assim, o leitor acompanha a história da língua desde sua diferenciação do latim até o chamado neorrealismo português. Concebendo a história da literatura como história da língua literária, foi possível, ao mesmo tempo, construir a especificidade do objeto e inseri-lo

\footnotetext{
${ }^{2}$ A expressão é de Furet, que a aplica a História, disciplina que, na França posterior à Revolução de 1789, se converteria numa narrativa do desenvolvimento da nação (1979).
} 
no conjunto da cultura europeia, pois o português literário se constitui a partir de uma cultura e de uma história comum, que vai se diferenciando na constituição dos diversos idiomas. Assim, um problema que afligia Candido na Formação é resolvido facilmente no texto de Saraiva e Lopes: a literatura portuguesa faz parte das literaturas europeias, a história de cada uma dessas seria o processo de sua diferenciação, que se dá sem que se percam os vínculos que perfazem a unidade.

Contudo, se a literatura é entendida fundamentalmente a partir da língua, surge um problema que seria justamente a relação entre as letras portuguesas e brasileiras. É preciso responder como é possível sustentar a especificidade se o idioma é o mesmo. A resposta dos autores portugueses é fazer da nação um segundo critério que, junto com a língua, garantiria a especificidade da literatura. Deste modo, apesar de partilharem o mesmo idioma, constituiriam literaturas diferentes em função do critério "nação", e, como Candido, Saraiva e Lopes sustentam, no caso dos tempos da colônia, é difícil e anacrônico definir se autores como Gonzaga ou Cláudio Manuel são portugueses ou brasileiros, mas se deveria tomar a Independência como marco simbólico da separação das duas literaturas. A postura é muito semelhante à assumida por Candido, que usa o termo "literatura comum" para afirmar o entrelaçamento destas até meados do século XIX (cf. CANDIDO, 1959, p. 28).

Se para Candido a literatura brasileira é um galho da portuguesa, podese dizer que suas histórias até certo momento formam uma unidade, e a própria continuidade linguística sustentaria essa ideia. No entanto, não é a língua o critério decisivo para pensar a especificidade da literatura na Formação. Se fosse, Candido teria que enfrentar a questão de como o idioma literário se transforma ao longo da experiência colonial, justificando sua separação do português literário da antiga metrópole. O critério decisivo na Formação é sociológico, a formação do sistema literário de dimensões nacionais. Na História da literatura portuguesa, a ideia de nação era um operador subordinado que permitia, numa espécie de sintonia mais fina, postular a especificidade da literatura portuguesa em relação à brasileira, já que sua diferenciação das outras literaturas europeias se dá à medida que cada uma dessas participa da elaboração de um idioma literário específico, como se a história das letras europeias fosse a narrativa do processo de constituição de uma série de línguas literárias a partir da literatura latina.

Se o principal critério de distinção é a formação do português literário, ou o desenvolvimento dos diversos idiomas literários europeus a partir 
de um fundo comum, ainda é preciso separar as literaturas portuguesa e brasileira, e é aí que entra o critério sociológico no próprio Antonio José Saraiva. Se o autor poderia sustentar a tese da diferenciação da língua nos dois países e defender a especificidade sem recorrer ao conceito de nação, é outro problema, mas parece que ele não considerava a variação linguística entre os dois países tão significativa a ponto de ser decisiva nessa questão, perspectiva que Candido partilha e que talvez pudesse explicar o predomínio do sociológico na Formação, apesar de o crítico inúmeras vezes defender que o fator estético ou a função total subordina a função social, pois se um critério linguístico não separa as literaturas portuguesa e brasileira, o critério nacional o faz.

Num texto escrito em 1987, Iniciaçãoà literatura brasileira, Antonio Candido reafirma que esta pertence organicamente ao conjunto das literaturas ocidentais, acrescentando que estas "foram se constituindo lentamente, ao mesmo tempo em que se formavam os respectivos idiomas" (CANDIDO, 1999, p. 11). Se no caso europeu a língua, a literatura e a sociedade se formaram conjuntamente, o mesmo não aconteceu no Novo Mundo, para onde teriam se transplantado línguas e literaturas já formadas. A literatura chega ao Brasil com a língua portuguesa já desenvolvida, deixando claro por que, para Candido, a história da literatura brasileira não poderia ser uma história da língua, pois essa teria ocorrido em Portugal e chegaria concluída ao Brasil, onde o idioma literário, ou como diz o autor, a "palavra culta do Ocidente", precisou assumir "novos matizes para descrever e transfigurar a realidade" (CANDIDO, 1999, p. 13).

Excluindo a língua como fator constitutivo da especificidade da literatura brasileira, pois a diferença é apenas uma questão de nuances, variações na forma de expressão, que são resultantes da nova situação, resta o critério sociológico, que permite operar a "síntese" das tendências particularistas e universalistas, garantindo a singularidade da literatura brasileira ao mesmo tempo em que a inscreve na tradição literária europeia.

"A sociedade colonial brasileira não foi, portanto (como teria preferido que fosse certa imaginação romântica nacionalista), um prolongamento das culturas locais, mais ou menos destruídas. Foi transposição das leis, dos costumes, do equipamento espiritual das metrópoles. A partir dessa diferença de ritmos de vida e de modalidades culturais formou-se a sociedade brasileira, que viveu desde cedo a difícil situação de contacto entre formas primitivas e formas avançadas, vida rude e vida requintada. 
Assim, a literatura não "nasceu" aqui: veio pronta de fora para transformar-se à medida que se formava uma sociedade nova".

(CANDIDO, 1999, p. 12).

A sociedade colonial não é pensada como prolongamento das culturas locais ou africanas, ou como um equilíbrio de antagonismos entre estas e os padrões europeus. Para Candido, ela teria sido a transposição de modelos metropolitanos que formavam nos trópicos uma sociedade à europeia, a formação da literatura seria parte do processo através do qual a linguagem culta do Ocidente se impôs sobre o Novo Mundo, garantindo que o difícil contato entre as formas avançadas e primitivas de cultura se resolvesse pela dominação e legitimação dos padrões europeus. Essa perspectiva já aparecia na Formação, em que a literatura, principalmente através das associações literárias do século XVIII, aparece como um instrumento usado para dominar a cultura de cunho popular, que coexistia com a cultura erudita de matriz europeia que se pretendia impor. As associações:

"no caso da colônia brasileira [...] representavam neste sentido, um reforço da política de imposição da cultura erudita de tipo europeu, em detrimento das manifestações de cunho popular, que assumiam relevo ameaçador em certos casos. Há mesmo vários exemplos de coexistência das duas culturas em certas comemorações, revelando a concorrência e a necessidade de consolidar a de tipo europeu".

(CANDIDO, 1959, p. 75).

Solidária do processo de colonização, a literatura nos trópicos veicula os valores ocidentais. Note-se que Candido não está pensando a literatura como a expressão de uma cultura miscigenada, ou como resultado do diálogo entre diferentes tradições. Se aqui aparecem duas culturas, uma tenta subordinar a outra, e o sistema literário que se constitui se enraíza no campo erudito da cultura.

Enquanto forma de transmissão de valores ocidentais no contexto colonial, a literatura pode ser pensada como um dos meios através dos quais o "espírito do ocidente" encontra uma "nova morada" nesta parte do mundo (cf. CANDIDO, 1959, p. 10). E esse processo se consolida através da formação do estado nacional, a instituição que materializaria o projeto de constituição de uma sociedade ocidental nos trópicos. A literatura brasileira se distingue da portuguesa porque participa do processo de formação da nação, entrelaçando os conceitos de literatura (através do sistema literário) 
e o conceito de nação.

Em Formação da literatura brasileira encontra-se uma concepção de literatura como parte integrante do processo de constituição do social, uma concepção de literatura como um artifício, um instrumento que termina por consolidar uma tradição. Nessa perspectiva, a nação não é anterior à literatura, como uma essência que esta exprimiria, também não se trata da história da constituição de um sistema cultural que se acrescentaria ao sistema social. Na Formação, literatura e nação, sistema cultural e social se desenvolvem simultaneamente, a nação não está nem antes nem apenas depois daquilo que Candido chama de sistema literário, está durante.

No prefácio à primeira edição de Formação da literatura brasileira já é possível perceber a ideia da literatura como instrumento de um processo civilizador. A literatura brasileira contemporânea é apresentada como algo recente que se formou a partir da portuguesa, e que, por sua vez, forma os indivíduos através de sua incorporação à cultura ocidental.

Conceber a literatura como fonte de civilização parece implicar, para o autor, o reconhecimento dos padrões universais que a regiam e que possibilitariam que a cultura brasileira se desenvolvesse articulando-se à cultura europeia, de modo que as particularidades locais seriam variações no interior do projeto civilizador, uma atualização específica do espírito ocidental.

\section{Além da ordem: os ensaios posteriores a 1964}

O processo discutido em Formação da literatura brasileira pode ser entendido a partir de duas dimensões que se superpõem, ambas relacionadas ao conceito fundamental que dá título ao livro. A formação é a Bildung da cultura nacional, um processo através do qual a tradição ocidental e a "realidade" local se interpenetram numa articulação entre o universal e o particular, que permite que a atmosfera cultural brasileira se torne mais densa, constituindo sua própria tradição, vinculando gerações e transmitindo o passado para o presente, como um espírito que, apesar das diferenças, é constituído por valores significativos para a contemporaneidade (cf. SAPIR, 1924, p. 325). Mas a formação seria também a história da construção da ordem literária nacional, que se entrelaça à produção da ordem social. $\mathrm{O}$ autor, na Formação, afirma que, durante a colônia, a literatura, através dos grêmios e associações, atuou "reforçando a cada passo a estrutura vigente de dominação [sendo] um reforço da política de imposição da cultura erudita 
de tipo europeu, em detrimento das manifestações de cunho popular, que assumiam relevo ameaçador em certos casos" (CANDIDO, 1959, p. 75). Em Literatura de dois gumes (1969) e na Introdução à literatura brasileira (1999), Candido retoma a ideia de que a literatura no Brasil exerceu a função de impor a cultura dominante, participando do processo de dominação e subordinação político-social.

No ensaio de 1968, Esquema de Machado de Assis, o tema da formação como Bildung e como construção da ordem está presente, mas há também a percepção de que a obra de Machado teria níveis mais profundos que mantêm uma relação mais crítica com a realidade social do que o cânone estabelecido na Formação. A obra de Machado de Assis, por baixo de uma camada epidérmica, que teria permitido perceber no autor apenas um "ironista ameno", porém "elegante", possui dimensões que o revelam como "o criador de um mundo paradoxal, o experimentador, o desolado cronista do absurdo" (CANDIDO, 1968, p. 24). Revelando uma compreensão profunda tanto dos "sigilos da alma" quanto das estruturas sociais, Machado de Assis desmistificaria o seu mundo através de uma visão ao mesmo tempo "terrível" e "lúcida" (cf. CANDIDO, 1968, p. 37). A literatura de Machado não parece se enquadrar, totalmente, no conceito de arte de agregação, que é a arte que, para Candido, atua como um fenômeno de integração social, reforçando os valores coletivos. Seria possível, portanto, encontrar uma outra relação entre a literatura e a ordem social que não esteja marcada pela "integração"..

Da mesma forma que a relação entre a literatura de Machado com a ordem difere do modelo de integração defendido na Formação, outros ensaios de Candido possibilitam encontrar movimentos na literatura brasileira do século XIX que destoam do projeto de construção da ordem. A educação pela noite, Dialética da malandragem e De cortiço a cortiço são textos privilegiados para identificar um movimento que se contrapõe àquele realizado na Formação, pois, ao invés de buscar a ordem e a coerência, nesses textos o autor percebe na literatura uma contracorrente que entra em conflito com a norma, sem que o sistema possa absorver ou neutralizar a diferença. Essa neutralização, na Formação, pode ser percebida através da estratégia de leitura que Candido desenvolve para demonstrar a articulação de Álvares de Azevedo ao sistema, autor que à primeira vista se afastaria da literatura empenhada na construção da nação.

A segunda geração romântica, à qual esse poeta pertencia, era formada por escritores "mais voltados para o próprio coração (segundo o conselho 
de Musset) do que para a pátria, Deus ou o povo, como os da primeira e terceira gerações" (CANDIDO, 1959-II, p. 134). Seria de se esperar que essa segunda geração se inserisse de modo distinto no sistema literário ou que a ele fosse contraposta. Contudo, quando o autor apresenta as características definidoras desse grupo, e que seriam a falta de equilíbrio, o culto da improvisação, a pressa, a inspiração ardente, uma sensibilidade adolescente, não deixa de acrescentar que:

\begin{abstract}
"Mas como estas características correspondem de certo modo às do brasileiro, e como a atmosfera do tempo fez com que eles as manifestassem em alto grau de concentração, o seu valor é grande para a nossa literatura, como expressão de uma sensibilidade local. Imitadores de Byron, Musset, Esproceda (...) participam por aí da corrente geral do romantismo europeu, a que deram todavia matizes expressivos do nosso modo de ser".
\end{abstract}

(CANDIDO, 1959-II, p. 137).

Se num primeiro momento essa geração de românticos parece se afastar do sistema por carecer do senso de missão que teria atravessado a literatura brasileira, logo se revela a integração desses autores ao movimento de formação, pois as peculiaridades que exibiam representavam uma espécie de condensação das características dos brasileiros. A pretensão de expressar as camadas mais profundas da alma, exibida por esses poetas mais intimistas, associava-os às correntes do modernismo europeu, que buscavam uma sondagem do interior do homem, mas, ao seguir esse modelo, revelavam uma forma de sensibilidade própria ao brasileiro, pois se a palavra de ordem era revelar as camadas mais profundas da alma, os poetas locais, inevitavelmente, encontraram através da pesquisa lírica características, formas de expressão de sentimentos, toda uma economia de afetos que distinguia o brasileiro. Sem pretender exprimir a singularidade da pátria, em virtude de seu individualismo mais acentuado, esse grupo romântico que, ao invés de tematizar a nação, experimentava formas líricas de expressão do eu, terminava por expressar a particularidade do modo de ser brasileiro, integrando-se, também, ao sistema. Revelando seus sentimentos através da lírica, não poderiam deixar de revelar o Brasil, pois esses sentimentos são distintivos do brasileiro.

Além disso, o nacionalismo literário era tão forte que os jovens da segunda geração romântica "manifestariam verdadeiro remorso ao sobrepor-lhe os problemas estritamente pessoais ou ao deixá-la pelos 
temas universais e os cenários de outras terras" (CANDIDO, 1959-II, p. 16). Álvares de Azevedo aparece como o autor mais eloquente para manifestar essa relação ambígua da segunda geração romântica com o nacionalismo, pois o remorso teria adquirido dimensões estéticas no Macário. Neste texto, o poeta, mais interessado nos seus dramas íntimos do que na construção da nação, desdobra-se em dois personagens também poetas, um defensor do nacionalismo e, o outro, seu crítico. De acordo com Candido, o personagem Macário, que critica a artificialidade do indianismo, contestando a ideia de que o poeta estaria obrigado a lidar com temas nacionais, representaria a própria posição de Álvares de Azevedo. Através de seu personagem, o autor questionaria uma série de temas e atitudes que teriam, segundo o argumento da Formação, contribuído para gerar e consolidar o sistema.

Esse poeta seria um crítico do nacionalismo literário que havia sido hegemônico durante o processo formativo, mas se integrava ao sistema ao questionar esse nacionalismo. Assim, a produção destoante é inserida no conjunto do sistema, porque ela simplesmente não pôde ignorar a problemática comum que constituía a literatura brasileira. Ao assumir uma posição sobre o nacionalismo literário, ainda que contrária a este, Álvares de Azevedo situava-se, através do debate, no interior da tradição que se constituía. Neste sentido, para incluir o poeta, o sistema é apresentado como um campo de debates, como Álvares de Azevedo assumiu uma posição sobre o tema central que constituía o campo, passava a integrá-lo. Se, ao invés de criticar o nacionalismo literário, o autor o tivesse ignorado, talvez permanecesse fora da ordem cuja gênese se investigava.

No ensaio a Educação pela noite, também dedicado a Álvares de Azevedo, encontra-se uma abordagem distinta daquela presente na Formação. O autor é apresentado como um "antinacionalista decidido em termos de literatura" que mantém uma "atitude destoante do esforço central da crítica do tempo" (CANDIDO, 1981, p. 14). Até aqui nada de muito diferente em relação ao texto de 1959. Contudo, a análise combinada de Macário com Noite na taverna leva o autor a caracterizá-los como uma espécie de "anti-Bildungsroman", que tomando a noite como uma espécie de estado de sensibilidade, de disposição do espírito e não apenas como um fato externo, realiza uma espécie de "educação pela noite", pelo lado sombrio, pelas trevas da alma, diz o autor, que opera a "liberação das potências recalcadas no inconsciente" (CANDIDO, 1981, p. 18). Candido interpreta a Noite na taverna como uma continuação de Macário. No final desse último texto, Satan mostra a Macário, através de uma janela, um 
grupo de pessoas embriagadas, que seria o mesmo grupo embriagado que se encontra, contando histórias, na Noite na taverna. As histórias do grupo corresponderiam a uma exploração das fronteiras dúbias que constituem o homem - onde começa o homem, onde termina o animal; em que ponto a paixão se torna ferocidade, onde o instinto sucede a alma. A matéria das histórias "parece concebida e escolhida por Satan como episódio duma espécie de anti-Bildungsroman, que ele propusesse para a formação (às avessas) do seu pupilo" (CANDIDO, 1981, p. 16). Uma antiformação através do qual o "homem procura conhecer o segredo da sua humanidade por meio da desmedida, na escala de um comportamento que nega todas as normas" (CANDIDO, 1981, p. 16). Através das cinco narrativas que constituem a Noite na taverna revelar-se-iam as desarmonias da condição humana e a fragilidade das normas sociais, preparando o terreno para uma "pedagogia satânica" que cultiva o "lado escuro do homem". As normas não passam de frágeis convenções, e o espírito humano é dobrado por desejos ferozes e instintos irresistíveis que levam ao desvario, à crueldade e ao crime.

Ao longo do texto, Candido reconhece que essa leitura insere Álvares de Azevedo nas correntes sombrias do Romantismo internacional - Noite na taverna seria um "romance negro". A "educação pela noite" libera desejos inconscientes reprimidos pelas normas que constituem a civilização. Embora Candido não formule desse modo, sua análise, especialmente no que se refere à Noite na taverna, opõe o desejo à civilização, cujos parâmetros precisam ser violados para que aquele se satisfaça. Nesta perspectiva, as normas são percebidas fundamentalmente a partir de seu aspecto repressivo, e não produtivo, como seria possível dizer da Formação, na qual o projeto de construção da nação e o sistema literário se entrelaçam.

Em A educação pela noite a ênfase é posta sobre a tensão que Macário e A noite na taverna instauram entre as normas e o desejo, entre as forças repressivas e o inconsciente. A "pedagogia satânica" não é recuperada pelos valores estabelecidos, mesmo que a entrega aos desejos em Noite na taverna tenha consequências trágicas, estas não reforçam as normas, não são a prova de que as regras não deveriam ser violadas, não figuram como expiação para a transgressão. Os desenlaces trágicos não anulam a "educação pela noite", o ser humano permanece dilacerado, tomado por fortes desejos, que frágeis convenções tentam conter.

Isso não significa que Candido estivesse rompendo ou abandonando a tese elaborada por ele em Formação. Em Literatura de dois gumes (1969), 
Candido acentua a relação entre literatura e controle social, adotando uma linguagem mais radical do que aquela empregada na Formação, que, contudo, expressa o mesmo processo de construção e consolidação da ordem. E além dessa retórica mais crítica, que coloca ênfase em aspectos opressivos, há também uma outra diferença aparecendo no texto: a apreensão da literatura como um fenômeno de dois gumes: "a literatura foi atuante na imposição dos padrões culturais, e a seguir como fermento crítico capaz de manifestar as desarmonias da colonização" (CANDIDO, 1969, p. 172).

O texto literário seria, segundo o autor, dotado de uma "ambiguidade" que permitiria sua conversão num instrumento capaz de dar "voz aos que não poderiam nem saberiam falar em tais níveis de expressão" (CANDIDO, 1969, p. 178). Em Literatura de dois gumes, a ambiguidade do verbo literário transforma-se num possível instrumento de contestação social, à medida que permite que vozes que foram silenciadas na sociedade encontrem um canal de expressão.

A Dialética da malandragem é o texto mais significativo para pensar esse movimento em direção a uma literatura que não "constrói" a ordem.. Esse ensaio caracteriza o livro de Manuel Antonio de Almeida, Memórias de um sargento de milícias, como um romance malandro no qual os personagens respirariam a atmosfera de um "mundo sem culpa", no qual seria possível circular da esfera da ordem para a da desordem e reverter o movimento, num vai e vem contínuo entre o universo oficial das regras e leis para um mundo de prazeres ilícitos, num movimento pendular entre a ordem e a desordem. De acordo com Candido, o autor do romance acompanha com simpatia esse oscilar dos personagens entre os dois polos, suspendendo o juízo moral que corresponderia à ótica da classe dominante, que aspiraria a implantar a ordem na sociedade brasileira. O autor não valorizaria no texto o campo da ordem como portador de uma lógica que deveria se impor sobre o mundo, a fim de reduzir ao máximo os espaços marcados pela irracionalidade. Pelo contrário, esses espaços desordenados permanecem em equilíbrio com a esfera da ordem.

Discutindo o corpus da literatura brasileira contemporânea das Memórias, Candido retoma a perspectiva de que essa literatura se engajava no processo de construção da nação através das mais variadas tentativas de disciplinar a sociedade:

"Um dos maiores esforços das sociedades, através da sua organização e das ideologias que a justificam, é estabelecer a 
existência objetiva e o valor real de pares antitéticos, entre os quais é preciso escolher, e que significam lícito ou ilícito, verdadeiro ou falso, moral ou imoral, justo ou injusto, esquerda ou direita política e assim por diante. Quanto mais rígida a sociedade, mais definido cada termo e mais apertada a opção".

(CANDIDO, 1970, p. 47-8).

Construir a nação passaria pela construção desses pares de opostos e do estabelecimento de valores morais excludentes. A literatura brasileira do século XIX, investindo nos processos de integração da sociedade, participaria dessa tentativa de estabelecer esses pares antitéticos. Se não há civilização sem repressão, uma sociedade mais rígida seria aquela que permite pouca transigência na interpretação das normas estabelecidas, definindo-as com grande precisão e definindo um campo de valores positivos que deveriam ser assumidos por todos, com pouca margem de manobra. Se a literatura brasileira aparece, no ensaio, envolvida com esse processo de instauração de normas, o romance de Manuel Antonio permanece estranho a essa tentativa de civilizar o país, revelando uma relação distinta com os valores oficiais, pois, ao invés de tomá-los seriamente, mantém com eles uma atitude jocosa. A dialética da ordem e da desordem dissolve a rigidez das normas oficiais ao colocá-las em contato com a atmosfera que deveriam reprimir. A lei, a ordem, a norma se combinam a formas de comportamento transgressores, que tendem a negar o caráter absoluto a que elas aspiram.

Ao contrário da sociedade puritana norte-americana, em que cada coisa encontra o seu lugar num espaço moral plasmado pela lei, nas Memórias nada é inteiramente positivo ou negativo, e os extremos não geram, por sua rígida oposição, uma sociedade moral como a puritana, mas se dissolvem num "mundo sem culpa". Esse romance também destoaria das tentativas de construção da ordem ao deslocar seu centro de gravidade da cultura oficial para a cultura popular, num movimento contrário à instauração do "projeto civilizador", que supõe o progressivo controle da cultura popular pelas esferas sociais mais elevadas. Mergulhando na cultura cômica popular, o romance encontraria afinidades com o universo cultural brasileiro, marcado por uma atitude de "tolerância corrosiva, muito brasileira, que pressupõe uma realidade válida para lá, mas também para cá da norma e da lei" (CANDIDO, 1970, p. 53).

Um dos pontos altos desse ensaio é a comparação entre A letra escarlate e as Memórias. Chamando a atenção para o romance de Samuel Hawthorne, e também para o drama das feiticeiras de Salém, Candido pretende contrapor 
as experiências culturais brasileira e norte-americana. Na formação dos Estados Unidos a partir das colônias puritanas, a lei, civil e religiosa, esteve presente moldando o comportamento dos indivíduos dentro de limites bastante estreitos dados pela "força punitiva do castigo exterior e do sentimento interior do pecado" (CANDIDO, 1970, p. 50).

A Letra Escarlate provavelmente traduz para Candido esse processo de formação histórico através do qual tanto o indivíduo quanto o grupo se endurecem de modo a construir uma identidade muito forte, mas que provocaria uma espécie de desumanização das relações com os outros, sejam estes os membros de outros grupos, sejam aqueles que, inicialmente pertencendo ao grupo, revelam-se não eleitos através do pecado. Neste último caso estaria Hester Pryne, a personagem do livro de Hawthorne, condenada a exibir um " $\mathrm{A}$ " escarlate em suas roupas como sinal de seu pecado, o adultério.

De certa forma, esse modelo rígido buscava limitar a espontaneidade regulando ao máximo a conduta cotidiana. A falha individual traria consigo graves conflitos internos além da possibilidade de punição pela comunidade. Teríamos uma sociedade obcecada com a regra moral e que exigiria que os indivíduos vivessem suas vidas como se estivessem caminhando sobre uma linha reta da qual não poderiam se desviar sem sofrer severas consequências, uma sociedade moldada por princípios que podem ser encontrados no ascetismo cristão (WEBER, 1905). No interior de uma concepção que percebe no status naturae, a submissão do homem a instintos irracionais que o tornam preso a sua própria natureza, a ordem moral seria, no final das contas, a garantia de que os indivíduos poderiam se tornar livres, permitindo que o homem submetesse suas ações a princípios éticos, desenvolvendo um autocontrole racional de sua conduta (cf. WEBER, 1905, p. 102). A ascese através da qual os impulsos são reprimidos seria um instrumento através do qual o homem constrói um sólido domínio moral sobre si mesmo, tornando-o capaz de subordinar os desejos, deixando de ser um escravo das paixões. A repressão dos instintos seria para o puritano, e para seus herdeiros, uma condição para a liberdade ${ }^{3}$.

\footnotetext{
${ }^{3}$ A ideia de que a liberdade é condicionada pode ser paradoxal, ainda mais se sua condição é a repressão dos instintos, mas para o puritano não há paradoxo algum, pois o homem em status naturalis não é livre, mas prisioneiro dos instintos e do pecado (cf. WEBER, 1905, p. 205). A liberdade seria a capacidade de se colocar acima das paixões.
} 
“[Já] no Brasil, nunca os grupos ou os indivíduos encontraram efetivamente tais formas; nunca tiveram a obsessão da ordem senão como princípio abstrato, nem da liberdade senão como capricho. As formas espontâneas da sociabilidade atuaram com o maior desafogo e por isso abrandaram os choques entre a norma e a conduta, tornando menos dramáticos os conflitos de consciência".

(CANDIDO, 1970, p. 50-1).

As diferenças se relacionariam ao "mecanismo das respectivas sociedades", ou a estruturas profundas que teriam se produzido historicamente. Assim, de um lado estaria uma sociedade que através de uma "fraternidade enganadora" agia de modo a constituir-se como um "grupo idealmente monorracial e monorreligioso". Uma sociedade fundada na igualdade, que seria, no entanto, uma espécie de igualdade de seita, ou seja, aqueles que não apresentassem determinadas características consideradas como essenciais pelos "iguais" seriam excluídos da comunidade $^{4}$. E, de outro lado, a sociedade brasileira, que teria de fato incorporado o "pluralismo racial e depois religioso à sua natureza mais íntima" (CANDIDO, 1970, p. 51).

Mais flexível que coerente, a sociedade brasileira também comportaria dentro de si projetos de normalização, de civilização, entendidos como substituição da flexibilidade pela coerência. E a literatura brasileira da época, como já mencionado, estaria predominantemente envolvida com a tentativa de disciplinar a sociedade, que resultaria numa proliferação, em seus textos, de símbolos repressivos que deveriam limitar ou domesticar os impulsos que poderiam comprometer a civilização. Neste ponto, as referências a Alencar no ensaio são tão significativas quanto à abordagem de A letra escarlate.

"N'O guarani, a força do impulso vital, a naturalidade dos sentimentos, só ocorre como característica dos vilões ou, sublimados, no quadro exuberante da natureza -, isto é, as forças que devem ser dobradas pela civilização e a moral do

\footnotetext{
${ }^{4}$ Novamente Tocqueville pode ser esclarecedor. Depois de informar que em algumas colônias a falta aos cultos implicaria pagamento de pesadas multas, afirma que em outras se "chega a ponto de prescrever severas penas e até mesmo condenar à morte os cristãos que queiram adorar a Deus de uma forma diferente da sua" (TOCQUEVILLE, 1835, p. 38-39).
} 
conquistador, das quais D. Antônio de Mariz é um paradigma e o índio romântico um homólogo ou um aliado. (...) Repressão mutiladora da personalidade é ainda o que encontramos noutros romances de Alencar, os chamados urbanos, como Lucíola e Senhora, onde a mulher opressa da sociedade patriarcal confere ao enredo uma penumbra de forças recalcadas. Em meio de tudo, a liberdade quase feérica do espaço ficcional de Manuel Antônio, livre de culpabilidade e remorso, de repressão e sanções interiores, colore e mobiliza o firmamento do Romantismo (...)".

(CANDIDO, 1970, p. 49-50).

O contraste com Alencar e a literatura da época se estenderia à própria linguagem. Mesmo num romance crítico como Senhora, Alencar não comunicaria um senso de realidade, porque seu estilo teria se construído a partir de uma linguagem convencional e restrita a um grupo social. Já Manuel Antônio construiria um romance que no próprio plano do estilo mergulharia na cultura cômica popular dissolvendo as pretensões normativas das "ideologias" do século XIX.

“Esta [cultura cômica popular ou a "irreverência popularesca"] se articula com uma atitude mais ampla de tolerância corrosiva, que pressupõe uma realidade válida para lá, mas também para cá da norma e da lei, manifestando por vezes no plano da literatura sob a forma de piada devastadora, que tem certa nostalgia de valores mais lídimos, enquanto agride o que, sendo hirto e cristalizado, ameaça a labilidade, que é uma das dimensões fecundas do nosso universo cultural.

Essa comicidade foge às esferas sancionadas da norma burguesa e vai encontrar a irreverência e a amoralidade de certas expressões populares. (...) Ela amaina as quinas e dá lugar a toda sorte de acomodações (ou negações), que por vezes nos fazem parecer inferiores ante uma visão estupidamente nutrida de valores puritanos, como a das sociedades capitalistas; mas que facilitará a nossa inserção num mundo eventualmente aberto"

(CANDIDO, 1970, p. 53).

Candido, a partir das Memórias constrói a imagem de um universo cultural brasileiro antipuritano, maleável, irreverente, e que apresentaria uma série de características em comum com a descrição da cultura cômica popular feita por Bakhtin (1965). As Memórias teriam afinidades com o processo de carnavalização, que Bakhtin entende como uma forma de interação, através da qual elementos que estariam aparentemente em 
oposição, como o corpo e o espírito, o alto e o baixo, o sublime e o vulgar, o trabalho e a festa, a seriedade e o riso, são relacionados de forma a revelar a ambivalência desses termos. Nesse processo ocorre uma espécie de revitalização, pois o mergulho dos aspectos mais sérios da cultura no "baixo material e corporal", que caracteriza a cultura cômica popular, equivaleria a uma forma de regeneração, como se o envolvimento de certos aspectos da cultura nos temas do corpo, do sexo, da comida, por ângulos que não são experimentados nos níveis mais elevados da sociedade, pudesse atuar como um ventre que engole, enterra, mas restitui à vida. As normas mais rígidas são dissolvidas e reelaboradas, num processo que, como disse Candido, "amaina as quinas" e produz acomodações inesperadas entre esses valores que pareciam incomunicáveis. A carnavalização busca a maleabilidade e revela a aspiração por formas de sociabilidade orientadas "por valores mais lídimos" (CANDIDO, 1970, p. 53).

O autor propõe que as Memórias têm correspondências com a experiência dos homens pobres livres, com uma visão do mundo construída a partir de um enraizamento muito particular na vida social. Por essa razão, o romance de Manuel Antônio se afasta do projeto comum da literatura brasileira de sua época, que, mesmo na Dialética, poderia ser definido nos termos da Formação, pois nesse ensaio o corpus literário brasileiro é contraposto às Memórias, pois estaria envolvido com o projeto de disciplinar a vida nacional. Nesse sentido, a perspectiva de Alencar, como apresentada no ensaio, se aproximaria da experiência do mundo de outro grupo social, aquele comprometido com a construção da ordem. Assim, se, como disse o autor, num livro como Lucíola, a personagem feminina "confere ao enredo uma penumbra de forças recalcadas" (CANDIDO, 1970, p. 50), que explodem na sua "sensualidade desenfreada" (CANDIDO, 1959-II, p. 207), o enredo conduz ao controle dessas forças, que devem ser reprimidas, não liberadas. Lucíola é um romance que se movimenta da transgressão para a ordem, unilateralmente. Não há a via de mão dupla que caracteriza as Memórias, já que a sensualidade excessiva de "Lucíola" é substituída pela "santidade" de "Lúcia", pecadora arrependida e penitente.

Na Dialética da malandragem, Candido coloca em cena uma forma de cultura popular que se contrapõe a determinados projetos de construção da ordem, que corresponderiam a uma relação distinta com o mundo social. E propõe que a visão de mundo particular expressa nas Memórias teria se integrado à cultura nacional. Contudo, não seria um traço cultural que daria conta do que é o Brasil em sua totalidade, mas uma espécie de 
fragmento que permite uma visão particular do todo. Se o ensaio contrapõe as Memórias a A letra escarlate, a dialética da malandragem ao puritanismo, há uma oposição interna no interior da própria sociedade brasileira, entre o corpus da literatura nacional e o romance em questão, entre a experiência social de um grupo particular com a de outras camadas sociais. Ou seja, a dialética da malandragem não revela a visão que o autor tem da sociedade brasileira, revela uma imagem possível dessa sociedade, construída, segundo o autor, a partir de uma experiência particular da vida social.

Em De cortiço a cortiço (1991), Candido apresenta uma imagem do Brasil que difere tanto daquela que podemos apreender na Formação, quanto daquela presente na Dialética da malandragem. Em $O$ cortiço de Aluízio Azevedo, o mundo do trabalho e da exploração econômica dissolveriam a fábula do mundo sem culpa, da sociedade "malandra". Ao invés da atmosfera um tanto carnavalesca que caracteriza as Memórias, O cortiço é marcado, segundo Candido, pelo trabalho, que aparecerá ao mesmo tempo como modo de disciplinar asceticamente o meio natural e social e como forma de exploração.

Tomando como ponto de partida um dito popular do final do século XIX que equiparava portugueses, negros e burros, "para português, negro e burro três pés: pão para comer, pano para vestir, pau para trabalhar", Candido relaciona a perspectiva desenvolvida na Dialética da malandragem com a que norteia $O$ cortiço. $O$ mundo sem culpa pertenceria à visão de mundo e às práticas sociais dos homens livres pobres, que, situados entre as classes dirigentes e os escravos, sonhavam com estratégias de sobrevivência que lhes permitissem viver a boa vida, escapando da necessidade de trabalhar. $\mathrm{Na}$ análise de Candido, o dito que equiparava portugueses, negros e burros traduziria não só atitudes racistas, como uma recusa ao trabalho e um certo despeito ou mesmo ódio pelo português, que trabalharia como um negro escravo, mas que poderia enriquecer. Branco livre, o brasileiro pensaria o trabalho como uma mácula, o português tornava-se alvo, porque, além de ser mais branco, abraça o trabalho de tal modo que o converte em fator de enriquecimento. Além de odioso, esse estrangeiro é um personagem ambíguo, pois trabalha como um inferior, é branco e enriquece, colocandose num nível economicamente elevado.

"O brasileiro livre que riu dele (do português) pela piada e o dichote fica, como se dizia no tempo, "a ver navios", porque tendia à boa vida e, nessa sociedade que fingia prolongar as 
ordens tradicionais, o trabalho era o ovo de Colombo que permitia ascender e desvendar cada vez mais a sua verdadeira divisão em classes econômicas".

(CANDIDO, 1991, p.130).

Contudo, em $O$ cortiço, dois elementos anticivilizatórios, a "raça" e a natureza tropical, aparecem em $O$ cortiço oferecendo resistência à construção da ordem.

“No Brasil, quero dizer n'O cortiço, o mestiço é capitoso, sensual, irrequieto, fermento da dissolução que justifica todas as transgressões e constitui em face do europeu um perigo e uma tentação. Por isso, não espanta que João Romão encarasse e manipulasse essa massa inquietadora com o desprezo utilitarista dos homens superiores de outra cepa".

(CANDIDO, 1991, p. 139).

A raça é um fator anticivilizatório porque a sensualidade do mestiço atua como solvente das disciplinas civilizadas, representando uma tentação para o europeu, que, se não conseguir vencê-la, será por ela dominado. A natureza também é uma ameaça a ser vencida, posto que a "natureza brasileira" "desempenha papel essencial como explicação dos comportamentos transgressivos, como combustível das paixões e até da rotina fisiológica". No romance de Aluízio Azevedo, a natureza tropical seria "incompatível com a ordem e a ponderação dos costumes europeus" (CANDIDO, 1991, p. 138).

Cercados pela sensualidade mestiça, que tem seus efeitos potencializados pelo clima, os portugueses, que desejam "fazer a América", encontrariam na dedicação ascética ao trabalho a única proteção contra as seduções do clima e da "raça". Esse é o caso do personagem João Romão, que, em sua ascensão, explora tanto a natureza quanto a "massa inquietadora" que habitava o cortiço. Seu "desprezo utilitarista" lhe permite resistir às potências anticivilizatórias, submetendo-as a seu projeto de acumulação de capital, ou seja, "civilizando-as".

Se os portugueses, contudo, aparecem como agentes civilizadores, nem todos conseguem resistir aos perigos e tentações dos trópicos. Como o português Jerônimo que se apaixona pela "mestiça" Rita Baiana:

“Tudo culmina numa aceitação triunfal da natureza, num gosto crescente pela "luz selvagem e alegre do Brasil". Por isso, quando 
lamenta a perda do marido que foge com a baiana, a sólida Piedade de Jesus, sua mulher, levanta os punhos cerrados para um céu que não é instância divina, tão diversa como diz da paisagem tranquila de sua terra, que não favorecia aos sentimentos desvairados".

(CANDIDO, 1991, p. 141).

De acordo com Candido, a dinâmica d' $O$ cortiço pode ser pensada como um jogo do espontâneo e do dirigido. $\mathrm{O}$ espontâneo corresponderia à tendência para uma organização social não disciplinada, representada pela sociabilidade inicial do cortiço, que sucumbe, até com prazer, às pressões do meio e da raça. $O$ dirigido seria por sua vez representado pela atuação de um projeto racional capaz de submeter essas duas potências dissolutoras. Aqueles que se entregam ao espontâneo, à sensualidade da natureza e dos mestiços não mais se distinguem destes últimos, e também terminam explorados e dominados.

Nessa interpretação de Candido, a atmosfera d'O cortiço é muito similar à que se respira em Retrato do Brasil. A raça e o meio estão marcados pela mesma desmedida que potencializou a cobiça e a luxúria dos colonizadores e que teria se reproduzido através do tempo, convertendo-se numa constante nacional. A fadiga e o excesso, a luxúria e a melancolia poderiam ser utilizadas para caracterizar a interpretação que Candido faz da imagem que esse romance apresenta do Brasil. A grande diferença em relação a Paulo Prado é que, na interpretação de Candido, o fator dirigido parece ser capaz de ir enfrentando e explorando o espontâneo, de modo que seu projeto racional pode se estabelecer sem a necessidade de um evento catastrófico, como uma guerra ou uma revolução, que permita recomeçar a história brasileira, eliminando os males legados pela experiência colonial.

Paulo Prado também recorre ao caso norte-americano, pensando-o a partir da experiência puritana, caracterizada por fortes valores morais que teriam permitido construir uma próspera sociedade. O autor constrói essa imagem dos Estados Unidos para dispor de um modelo que se contraponha à efervescência e à fragmentação características, segundo sua visão, da sociedade brasileira. O modo como Candido interpreta João Romão permite dizer que esse personagem encarna atitudes que se aproximam da conduta puritana, ainda que ele não se oriente pelo código moral que a norteava. Em seu pragmatismo, o personagem representaria uma antítese à imagem efervescente e fragmentada que caracterizaria o Brasil de $O$ cortiço. A interpretação de Candido desse romance coloca em cena uma visão do Brasil muito semelhante àquela construída por Prado, contudo, encontra no 
personagem português que resiste às tentações do ambiente um substituto para o puritano enquanto agente disciplinador, capaz de submeter a "natureza" e a "raça" ao projeto de acumulação de capital.

Na interpretação de Candido, o cortiço seria "um Brasil em miniatura" (CANDIDO, 1991, p. 137), um Brasil que aparentemente está em contradição com a sociedade apresentada nas Memórias de um sargento de milícias. $\mathrm{O}$ autor resolve a diferença indicando que, enquanto as Memórias têm afinidades com a visão de mundo dos homens livres da primeira metade do século XIX, O cortiço aproxima-se do pessimismo dos intelectuais brasileiros do final desse mesmo século, que julgavam a mestiçagem e o clima como entraves à construção da civilização no Brasil.

Tanto o ensaio sobre as Memórias quanto este sobre $O$ cortiço operam com imagens do excesso, da desmedida como marcas da sociedade brasileira apresentada nos romances. Enquanto no primeiro os excessos, inclusive os sexuais, garantem a harmonia e o final feliz, no segundo estes se manifestam, sobretudo, rebaixando a vida social. O polo que o autor chama de espontâneo é constituído por formas de sociabilidade quase lúdicas e de certa forma livres que se revelam frágeis diante do projeto civilizador que o polo dirigido representa.

No ensaio sobre $O$ cortiço, a análise de Candido aponta para uma visão do Brasil em que o excesso, o descontrole e a irracionalidade estariam presentes o tempo inteiro, representando obstáculos que, a partir da ótica do projeto de civilizar o país, ou simplesmente de acumular capital, teriam que ser subordinados. Ainda segundo o autor, como no romance a desmedida, resultante do clima e da sensualidade da "raça", domina o brasileiro, ela só pode ser vencida por estrangeiros, que em virtude do mencionado "desprezo utilitarista por homens de outra cepa", resistiriam à sedução tropical e submeteriam os brasileiros aos seus projetos.

No ensaio sobre as Memórias, a imagem da desmedida pode ser percebida de forma positiva, redimindo a vida social, enquanto em $O$ cortiço, a hybris rebaixa, inferioriza ${ }^{5}$. Se cada um desses textos produz uma imagem distinta do país, talvez não seja impróprio sugerir que o autor esteja discutindo ou apresentando fabulações distintas sobre este. Os ensaios seriam

\footnotetext{
${ }^{5}$ Tomo a ideia de hibrys, da desmedida, possuindo potencial tanto para rebaixar quanto para redimir relações do estudo de Ricardo Benzaquen de Araújo sobre Gilberto Freyre (ARAÚJO, 1994).
} 
tentativas de compreender "invenções" diversas do Brasil. Cada ensaio é a experimentação de uma forma de pensar a nação que aparece na literatura. Cada uma dessas formas poderia ter afinidades com perspectivas e práticas sociais presentes na sociedade, revelando um vínculo entre a literatura e a experiência do mundo.

Enquanto na Formação explorava-se um caminho que implicava a exclusão de concepções alternativas, já que todo cânone se estabelece por exclusão, em alguns ensaios de Candido percebe-se um movimento em direção a sentidos do texto que escapam do sistema. A tese defendida na Formação supõe que os textos literários se integram coerentemente num sistema, excluindo as manifestações do fenômeno literário que não se adequassem à ordem. Em ensaios posteriores à Formação, Candido explorou dimensões da literatura que não se integravam coerentemente à perspectiva da construção da ordem literária nacional. Deste modo, $\mathrm{o}$ autor pôde "ouvir" vozes, em alguns textos, que não eram coerentes com a ideia do sistema. E como o autor sempre buscou na literatura vínculos com a experiência do mundo, o gênero ensaio permitiu a maleabilidade para explorar diferentes imagens da sociedade brasileira, diferentes visões de mundo, que poderiam ter afinidades com modos distintos de inserção na vida social.

\section{Uma dialética negativa?}

"Se minha alma pudesse firmar-se, eu não me ensaiaria, decidir-me-ia." (MONTAIGNE, 1588, III, II, p. 28)

Logo, em alguns ensaios, Candido experimentou uma forma de abordagem do texto literário que, se não desconstruía o argumento da Formação, dele divergia. O tema desse livro é a integração da literatura num sistema coerente que contribuía para a consolidação da cultura e da identidade nacional.

Nos ensaios discutidos, especialmente na Dialética da malandragem, a ordem está presente como um contraponto, um fundo contra o qual se destacam textos que tinham faces diversas daquelas que caracterizavam o sistema. É evidente que, sem a suposição de que o corpus da literatura brasileira tenta disciplinar a sociedade, a dialética da ordem e da desordem se descaracterizaria, pois o próprio Candido supõe que esse texto representa uma tendência distinta daquela que seria predominante nos romances 
brasileiros do século XIX.

Em De cortiço a cortiço o tema da ordem também pode ser encontrado no caso não associado à formação do cânone, mas como uma ordem repressiva que tenta conter a indisciplina tropical, como um projeto de racionalização, que civiliza ao mesmo tempo em que transforma pessoas em objetos que possibilitam a acumulação de capital. Pode-se dizer que a interpretação que Candido faz de $O$ cortiço capta duas imagens negativas do Brasil, de um lado uma imagem semelhante àquela que Paulo Prado construíra em Retrato do Brasil. Uma imagem segundo a qual este seria um país marcado pelo excesso, onde a sedução da natureza potencializa a sedução das "raças" exóticas para o branco europeu, contribuindo para que a cobiça e a luxúria do aventureiro português dos primeiros séculos da colonização se tornassem uma marca na psiché do brasileiro, inviabilizando a construção de uma autêntica sociedade. A outra imagem se refere ao próprio processo civilizador em curso no país, um processo que se dá através da acumulação capitalista, que reprime as forças anticivilizatórias e impõe a ordem como meio de maximizar a exploração econômica.

Contudo, não se trata apenas da afirmação de que os trópicos abrandam a disciplina europeia e de que a sensualidade das "raças inferiores e mestiças" ameaça dissolver o autocontrole do indivíduo europeu. Mesmo na Formação aparece a ideia de que os trópicos têm que ser disciplinados pela civilização europeia, só que esse processo de contenção dos fatores anticivilizatórios seria, neste livro, algo claramente positivo. É preciso conter tendências mais dissolventes ou anárquicas para que se consolide a nação. Ou seja, a perspectiva da Formação apresenta explicitamente o processo de colonização como o processo civilizador que promove a integração da colônia à cultura ocidental, preparando o terreno para a difusão de valores universais representados por essa cultura. $\mathrm{O}$ autor assume sem ironia, hesitação ou ambiguidade o ideal da civilização ${ }^{6}$. No ensaio sobre

\footnotetext{
${ }^{6}$ Costa Lima (1992) sustenta que, na Formação, Candido opta por uma atitude descritiva, que frequentemente "termina por endossar o que descreve" (COSTA LIMA, 1992, p. 167). Creio que este seria o caso no que diz respeito à avaliação do processo colonizador/civilizador. Candido opta por expor o processo tal qual ele se constituiu no Brasil, considerando que seu livro não seria o lugar para julgar este processo, mas para considerá-lo "realisticamente" como um dado. De acordo com Costa Lima, a descrição em Candido "será o meio de conciliar os contrários. Em conseqüência, sem que o explicite, o historiador termina por endossar o que descreve" (COSTA LIMA, 1992, p. 167).
} 
O cortiço, a questão se constrói de um outro modo: os dois lados do dilema, a civilização e a barbárie, são apresentados como problemáticos, nenhum dos dois é apresentado como inteiramente positivo. Não se trata do conflito entre a indesejável barbárie tropical e um processo civilizador que difunde a razão ocidental, pois este último é, antes de tudo, um processo repressivo de acumulação de capital.

No enredo da Formação, a ordem da civilização é um valor positivo que orienta a análise, que busca compreender como a literatura compôs no Brasil uma cultura de tipo ocidental. Neste sentido, o processo é visto de um ângulo positivo, a partir de um ideal social7: a construção do sistema e a formação da nação. Cada texto é pensado a partir de sua correspondência ao ideal, e, neste sentido, a abordagem da Formação tem algo de normativo, como a exclusão das "manifestações literárias" anteriores ao Arcadismo revela.

A literatura, neste livro, é pensada fundamentalmente como uma expressão do ideal de construção da nação e revela como em dois momentos fundamentais, o Arcadismo e o Romantismo, esse ideal começou a se desenhar e adquiriu crescente nitidez. O ideal social que orienta o enredo, a tendência histórica que conjugava literatura e nação levam à apresentação da experiência literária basicamente através da noção de coerência, ou de integração sistêmica, o que equivale a tomar como um critério decisivo, na avaliação do texto, o grau de sua adequação à ordem. No enredo da Formação a literatura não poderia aparecer como uma radical contestação das normas, pois mesmo a contestação arcádica se dá a partir de um ideal normativo, que a coroa ou a administração portuguesa estaria violando, não os colonos. Porém, ainda que se reconheça nesse movimento a ruptura com algumas normas, não configura uma autêntica crise de valores, pois os árcades internalizaram os mais avançados ideais ocidentais de sua época e lançam as bases sobre as quais se construiria a literatura no Brasil. Eles não representam uma cultura em crise, mas um momento de afirmação de conceitos e juízos que atravessariam a literatura brasileira. E esta só poderia integrar-se em sistema se, de algum modo, estivesse em contato com o ideal

\footnotetext{
${ }^{7}$ Retiro a noção de ideal social da crítica que Merquior faz à concepção de arte e literatura de Lukács. Para Merquior, o critério decisivo utilizado por Lukács, a partir de História e consciência de classe, para avaliar a obra de arte seria um ideal social, que define que "a obra será tanto melhor quanto mais acompanhe a saúde da sociedade" (MERQUIOR, 1969, p. 82).
} 
formulado, que a vinculava à construção da ordem nacional. À Formação, poder-se-ia aplicar o juízo de Merquior sobre Lukács: "o valor da arte se confunde com a saudável realidade que ela apresenta" (MERQUIOR, 1969, p. 83).

Se na Formação temos a articulação da literatura com um ideal social, constituindo critério essencial no entendimento de cada texto, em $D e$ cortiço a cortiço falta justamente essa articulação que permitia integrar os dois processos formativos, da nação e da literatura. Ao invés da boa ordem ou da saúde social, que Radcliffe-Brown (1935) traduz sob o conceito de eunomia, conceito que permitiria que o sistema literário fosse solidário da ordem social, esse ensaio parece fazer da experiência literária uma forma de problematização da experiência do mundo, que questiona o próprio equilíbrio do sistema.

Na leitura d'O cortiço, não há um ideal a que se apegar, o texto representa uma crise, pois nem a natureza tropical e a sensualidade mestiça, por um lado, nem o projeto civilizador em curso, por outro, representam alternativas positivas do ponto de vista do crítico. De cortiço a cortiço pensa seu objeto como se este se constituísse sob o signo da negatividade, como uma contestação do existente.

Encontra-se, portanto, nos ensaios de Candido, a partir do final da década de 1960 e início da de 1970, uma atitude diante da literatura distinta daquela que caracterizou a Formação. A ênfase não está mais na construção de um cânone, na demonstração do vínculo entre a construção da literatura e a construção da nação. Formação é escrita numa perspectiva totalizante, pois supõe fazer a história do sistema literário que já teria se formado e integrado. Cada texto analisado por Candido no livro se integra ao processo de constituição da literatura e da nação. Embora os textos não possam ser explicados pelo contexto histórico exclusivamente, talvez essa mudança de atitude em relação ao literário, que se torna mais sensível à diferença, explora em diferentes romances perspectivas distintas sobre a sociedade brasileira e possa ser relacionada à ruptura à democracia ocorrida com a ditadura de 1964.

Formação pôde relacionar literatura e sociedade numa dialética "afirmativa", que integra o texto literário à totalidade não apenas do sistema, mas da própria formação da nação, como um processo positivo, emancipador, apesar de tudo. Com a ditadura militar, a integração à totalidade revelaria, na verdade, uma face repressiva. O ensaio, enquanto forma, torna-se um gênero que permite a Candido explorar o que há de 
contestador na literatura, o que permanece fora da ordem, não se encaixa no sistema. Ao invés de um cânone que se integra a partir de uma missão comum e se confunde com o processo de formação da nação, o ensaio permitiu explorar diferentes ângulos, revelar o heterogêneo, colocar em questão o que permanecia fora da ordem, abordando o fenômeno literário em busca de múltiplas sondagens críticas do real.

\section{Referências}

ADORNO, Theodor

(1994). 0 ensaio como forma. In: Theodor Adorno; Sociologia. Coleção Grandes Cientistas Sociais (Gabriel Cohn Org.). São Paulo, Ática.

ANDRADE, Mário.

(1928). Ensaio sobre a música brasileira. São Paulo, Livraria Martins Editora.

ARAÚJ0, Ricardo Benzaquen de.

(1994) Guerra \& paz: Casa-grande \& senzala e a obra de Gilberto Freyre nos anos 30 . Rio de Janeiro, Editora 34.

(1988). Ronda noturna: narrativa, crítica e verdade em Capistrano de Abreu. Estudos históricos 1.

BAKHTIN, Mikhail

(1993). A cultura popular na Idade Média e no Renascimento: o contexto de François Rabelais. Brasília / São Paulo, UnB / Hucitec.

CANDID0, Antonio

(1957 [2000]). A literatura e a vida social. In: Literatura e sociedade: estudos de teoria e história literária. São Paulo, Publifolha.

CANDID0, Antonio.

(1959 e 1959-II [1997]). Formação da literatura brasileira. 2 volumes. Belo Horizonte, Editora Itatiaia.

CANDID0, Antonio.

(1997). Prefácio à 2a edição. Formação da literatura brasileira. 2 volumes. Editora Itatiaia, Belo Horizonte.
CANDID0, Antonio.

(1999). Introdução à literatura brasileira (conferência de 1987). Campinas, Humanitas.

(1995). Esquema de Machado de Assis. In: Antônio Cândido; Vários Escritos (terceira edição revista e ampliada). São Paulo, Duas Cidades.

(1970 [1993]). Dialética da malandragem. In: 0 discurso e a cidade. São Paulo, Duas Cidades.

(1991 [1993]). De cortiço a cortiço. In: 0 discurso e a cidade. São Paulo, Duas Cidades.

(1969 [1987]). Literatura de dois gumes. In: A educação pela noite e outros ensaios. São Paulo, Ática.

(1981 [1987]). A educação pela noite. In: A educação pela noite e outros ensaios. São Paulo,Ática.

COSTA LIMA, Luiz.

(1984). O controle do imaginário. São Paulo, Brasiliense.

COSTA LIMA, Luiz.

(1992). Concepção de história literária na Formação. In: Luiz Costa Lima; Dentro do texto, dentro da vida: ensaios sobre Antonio Candido. São Paulo, Companhia das Letras.

FURET, François.

(1975 [S/D]). Da história-narrativa à históriaproblema. In: François Furet; $A$ oficina $d a$ história. Lisboa, Gradiva. 
(1979 [S/D]). 0 nascimento da história. In: François Furet; $A$ oficina da história. Lisboa, Gradiva.

LACAPRA, Dominick.

(1982). Rethinking intellectual history and reading texts. In: LACAPRA, Dominick ; KAPLAN, Steven. (Ed); Modern European intellectual history: reappraisals e new perspectives. Cornell University Press, Ithaca and London.

MERQUIOR, José Guilherme.

(1969). Arte e sociedade em Marcuse, Adorno e Benjamin. Rio de Janeiro, Guanabara / Tempo Brasileiro.

MERQUIOR, José Guilherme.

(1979). 0 Texto como resultado (notas sobre a teoria da crítica em Antonio Candido). In Arinos, Afonso et all: Esboço de figura: homenagem a Antonio Candido. São Paulo, Duas Cidades.

PRAD0, Paulo.

(1997). Retrato do Brasil: ensaio sobre a tristeza brasileira. São Paulo, Companhia das Letras.

RADCLIFFE-BROWN, A. R.

(1978). Sobre o conceito de função nas ciências sociais. In: Estrutura e função na sociedade primitiva. Petrópolis, Vozes.

ROMERO, Sílvio.

(1880 [2001]). A literatura brasileira e a crítica moderna. In: Luiz Antonio Barreto (Org.); Literatura, história e crítica. Sergipe / Rio de Janeiro, Editora UFS / Imago.
(1888 [2001]). História da literatura brasileira (Edição Comemorativa). Sergipe / Rio de Janeiro, Editora UFS / Imago.

SAPIR, Edward.

(1924 [S/D]). Culture genuine, and spurious. Selected writings of Edward Sapir in language, culture and personality. In: David Mandelbaum (Ed). Los Angeles, University of California Press - Berkeley.

SARAIVA, Antonio José; LOPES, Oscar.

(1956). História da literatura portuguesa. Lisboa, Editora Europa América.

TOCQUEVILLE, Aléxis.

(1835 [1987]). A democracia na América. Belo Horizonte / São Paulo: Itatiaia / Edusp.

WEBER, Max.

(1905 [1990]). A ética protestante e o espírito do capitalismo. Lisboa, Editorial Presença.

\section{Recebido em}

setembro 2017

\section{Aprovado em}

outubro de 2017 